\title{
CATALOGACIÓN Y CONFORMACIÓN DEL MONTE DE UTILIDAD PÚBLICA: EL CASO DEL PIRINEO OCCIDENTAL ARAGONÉS
}

\author{
Juan Ramón DE LA RIVA FERNÁNDEZ \\ Departamento de Geografía y Ordenación del Territorio \\ Universidad de Zaragoza
}

\begin{abstract}
Resumen: Se aborda el proceso de conformación de una parte fundamental del extenso patrimonio forestal de la Jacetania: sus montes de utilidad pública. Se consideran primero las circunstancias que acompañaron en el marco de las reformas administrativas del S. XIX-al proceso de desamortización y se analiza el que fuera uno de sus resultados más positivos: la catalogación de los montes. Más adelante se evidencian algunas características básicas de estos predios a partir de los datos aportados por estas relaciones de montes que fraguaron en el Catálogo de 1901. Seguidamente se contempla el concepto de utilidad pública y se concluye con unas breves referencias a la situación actual de estos montes en la comarca.
\end{abstract}

Palabras clave: Catálogo de montes, Monte de Utilidad Pública, Jacetania.

\begin{abstract}
In this study, we would like to analyse the constitution process of an essential part of the vast forest inheritance in Jacetania: the Montes de Utilidad Pública (Public Utility Forests). After presentation of the circumstances surrounding -in the context of 19 th century administrative reforms- the policy of disentailment, we've considered the result which is the most important positive aspect of this: the forests' cataloguing. We've also evoluated some of the fundamental characteristics of these forests starting from the data contained in these catalogues; we've studied the concept of Public Utility and, finally, we've concluded with some references about the actual situation of these forests in the related area.
\end{abstract}

Key words: Forests Catalogue, Public Utility Forests, Jacetania.

\section{INTRODUCCIÓN}

La comarca más occidental del Pirineo aragonés -la Jacetania- constituye en la actualidad un espacio en el que la cubierta montuosa tiene carácter preponderante: tan apenas una décima parte de su superficie está cultivada, mientras que los bosques tapizan un tercio de sus casi trescientas mil hectáreas, los matorrales y montes bajos están presentes en una proporción semejante, el resto lo ocupan sus productivos pastos. En torno al $70 \%$ de la superficie comarcal es de propiedad colectiva, proporción que se 
eleva por encima del $90 \%$ en la mayor parte de los municipios situados al norte de 1 a Depresión Media (DE LA RIVA, 1989). En la actualidad, los montes de este territorio son explotados mayoritariamente en calidad de propios de los 24 ayuntamientos existentes; en el marco de diversas mancomunidades forestales es gestionada una parte sustancial, si bien coexisten muy diversas figuras jurídicas tanto en el ámbito de los comunales como de las propiedades privadas colectivas. Se suma a ello la presencia significativa de montes adquiridos por la Administración para su repoblación.

Una parte fundamental de este amplio patrimonio forestal jacetano está constituída por sus montes de utilidad pública; su importancia se manifiesta tanto en términos espaciales como en relación con las funciones que desempeñan: productivas, mediambientales, sociales... La explicación de su conformación y situación actual nos remite a un conjunto de reformas administrativas del monte iniciado en el S. XIX, desarrollado simultáneamente al proceso desamortizador, que concluyó aquí -como en toda España- con su catalogación.

Aunque la desamortización no tuvo, ciertamente, un impacto significativo en términos de superficies afectadas en la comarca, las circunstancias que rodearon el proceso y sus consecuencias se manifestaron en cambios importantes en la gestión y uso de los montes, máxime si se considera su conexión con la implantación de los métodos selvícolas de explotación ordenada, que en aquellos años tomaban fuerza. Por una parte, la desamortización sirvió para oficializar la artificiosa diferenciación entre bienes comunales y de propios, lo que vino a alterar el sistema de explotación y a suponer una merma importante en los derechos de los vecinos de los pueblos. No en vano, como señala GARCÍA DE ENTERRÍA (1976), la transformación de comunal a propios ha tenido una significación y gravedad mayor que el propio proceso desamortizador. Por otra parte, la declaración en estado de venta de los montes sentó las bases para su más profundo conocimiento y propició una mayor preocupación por ellos al fraguarse el concepto de Monte de Ltilidad Pública.

\section{LOS INTENTOS DESAMORTIZADORES Y LA CATALOGACIÓN DE LOS MONTES}

Un antecedente del proceso de transformación político-administrativa que iba a afectar a los montes se encuentra en las disposiciones de las Cortes de Cádiz ${ }^{1}$. En ellas se renegó abiertamente de la política precedente de tutela y protección de los montes por el Gobierno, considerando que atacaba la propiedad particular y que había propiciado el aprovechamiento caprichoso de los montes públicos con el consiguiente

${ }^{1}$ En el rastreo de la legislación relativa a montes es de gran utilidad ALCUBILLA $(1879,1923)$. 
aumento de las talas. Simultáneamente se otorgaba a los particulares una gran autonomía en la gestión de sus predios forestales ${ }^{2}$.

Aunque dos años más tarde tales disposiciones fueron derogadas (R.O. de 18 septiembre de 1814, que restableció la Real Ordenanza de 1748), era un signo evidente del nuevo rumbo que el Estado iba a dar a los patrimonios públicos. En 1818 se estableció el impuesto del veinte por ciento de propios, que incrementaba las cargas fiscales anteriormente existentes sobre este tipo de bienes, al que se sumaba además el $10 \%$ suplementario que gravaba los aprovechamientos forestales, tanto sobre comunales como sobre propios (MARTÍN-RETORTILLO, 1944; MANGAS, 1984). En 1836 se determinó -por Ley de 23 de noviembre- la absoluta libertad de actuación a los propietarios particulares, anulando las ordenanzas vigentes sobre montes y plantíos.

Ya entonces había cristalizado, en el ámbito de la propiedad forestal pública, la distinción entre propios y comunales, que se establecía en función de la existencia del pago de renta, por pequeña que esta fuera: serían de propios cuando generasen ingresos a los ayuntamientos, comunales cuando el uso fuera gratuito para los vecinos en su condición de tales. En aquellos años, el recelo oficial ante la autenticidad de los patrimonios comunales era evidente; la R.O. de 24 de febrero de 1838 estableció que deberían considerarse del Estado, además de los montes así definidos, aquellos que aun disfrutados por el común de los pueblos- no estuvieran avalados por documentos de propiedad. Se pedía, en consecuencia, que se informara sobre la legítima extensión de los bienes de propios, ya que los pueblos por efecto de las pasadas circunstancias -dice el texto- han solido apropiarse mucho de los de realengo. Un año más tarde, una circular (12 de noviembre de 1839) instó a los ayuntamientos a justificar la posesión de los montes comunales.

Existen referencias expresas a los montes jacetanos en una R.O. de 31 de marzo de 1846; en ella se dictaminó para éstos la obligación del pago del $20 \%$ de propios, por cuanto producen renta a los pueblos, cualquiera que sea su denominación. De gran interés en esta controversia es la R.O. de 22 de mayo de 1848, sobre montes del común de los pueblos y del común de los vecinos, que estableció la siguiente doctrina:

\footnotetext{
2 El Decreto de las Cortes de Cádiz del 14 de enero de 1812 sobre el régimen de libertad de los montes particulares y derogación de las leyes y ordenanzas contrarias a él afirmaba: "Las cortes generales y extraordinarias, con el justo fin de redimir los montes y plantíos de dominio particular de la opresión y servidumbre en que por un espíritu de mal entendida protección los han tenido hasta ahora las leyes y ordenanzas, tan contrarias al derecho de propiedad, como opuestas a la libre acción del interés individual (...) decretan: 1" Se derogan y anulan en todas sus partes todas las leyes y ordenanzas de monte y plantíos en cuanto conciernan a los de dominio particular (...) $2^{\circ}$ Los dueños tendrán igual libertad para cortar sus arboles y vender sus maderas a quien quisierer, y ni el estado, ni cuerpo alguno, ni persona particular podrá alegar para estas compras privilegio de preferencia o tanteo (...) $3^{\circ}$ (...) y sus dueños podrán cercarlos y aprovechar como quieran los frutos y producciones (....."
} 
"1. Que la legislación administrativa vigente no reconoce la diferencia que se pretende establecer entre los montes del común de los pueblos y del común de los vecinos. 2. Que es inadmisible el principio de que los vecindarios por sí y con independencia absoluta del Ayuntamiento y del Gobierno pueden disponer omnímodamente de dichos montes llamados del común de vecinos, asimilándolos con notoria equivocación a los de dominio particular. 3. Que todos los montes de propios o comunes, cualquiera que sea la época y origen de su adquisición están sujetos a las disposiciones generales que hoy rigen, en virtud de las cuales los vecinos no están autorizados para proceder al aprovechamiento de sus arbolados sino por medio de los Ayuntamientos, que son los administradores legítimos de los intereses comunales con arreglo a la ley."

Previamente a la que sería ley Madoz de desamortización general, el proceso de ventas afectó fundamentalmente a los bienes eclesiásticos. No conocemos con detalle el papel de estas enajenaciones en la Jacetania, aunque no debe suponerse relevante dada la escasa representación en aquel momento de señoríos y grandes propiedades eclesiásticas. GARCÍA-RUIZ (1974) afirma que al sur de la Depresión Media un cierto número de grandes fincas pudieron haber pasado a manos privadas de propietarios absentistas; algunas de ellas serían vendidas más tarde al Patrimonio Forestal para repoblación. No obstante, carecemos de información suficiente al respecto ${ }^{3}$.

La ley de desamortización de 1 de mayo de 1855 declaró en venta, entre otros, los propios y comunes de los pueblos, quedando exentos los terrenos de aprovechamiento común y los montes y bosques cuya venta no creyera oportuno el Gobierno. El texto, ampliamente conocido, lo refiere COSTA (1983) con algún comentario ${ }^{4}$ :

"Desgraciadamente, la hacienda de la nación se ha atrevido ya a poner la mano en este patrimonio de las generaciones venideras (...) Después de haberlo mermado abusivamente, enajenando grandes porciones de él con pretexto de propios, se ha apoderado como medida general del $20 \%$ de los que quedaban. La ley de $1^{\circ}$ de mayo de 1855 , que desamortizaba y declaraba en estado de venta, entre otros, los predios pertenecientes a los propios y comunes de los pueblos, exceptuó los terrenos que son hoy de aprovechamiento común, pero previa declaración de serlo, hecha por el gobierno, oyendo al Ayuntamiento y Diputación respectivos (art. 2), como igualmente la dehesa destinada o que se destine de entre los demás bienes propios del pueblo al pasto del ganado de labor de la misma población, donde no hubiese bienes de aprovechamiento común destinados a este objeto en cantidad suficiente, incoando expediente al efecto en término de un mes (...) Tal es al presente el deplorable estado de la legislación tocante a bienes comunales."

Consecuentemente, el Estado requirió a la Junta Facultativa del Cuerpo de Ingenieros de Montes que fijara los criterios para delimitar los montes y bosques a conservar.

\footnotetext{
3 Unicamente CALVO (1970) refiere la desamortización de la Pardina de San Salvador de Viasós (perteneciente al Monasterio de San Juan de la Peña) y su compra en 1836 por un vecino de Aísa que, mediante venta simbólica, la traspasó a los vecinos del pueblo.

${ }^{4}$ Sobre la evolución en los criterios de exención y, de forma más general, sobre la dimensión naturalista de la desamortización hay uln magnífico trabajo de GÓMEZ MENDOZA (1992). En relación con la propiedad y gestión de monte en los SS. XIX y XX existe un interesante monográfico de Agricultura y Sociedad $\left(\mathrm{n}^{7} 65,1992\right)$, alguno de cuyos artículos se cita en la bibliografía.
} 
Tras diversos avatares, se concluyó distinguiendo tres tipos de montes ${ }^{5}$ :

"Art. 1 Para los efectos prevenidos en el art 2" de la ley de 1" mayo último se dividen los montes y bosques del estado, de los propios y comunes y los de los establecimientos públicos en las tres clases siguientes: Primera. Montes que deben conservarse sujetos a las ordenanzas del ramo y que se se exceptúan por tanto de la enajenación. Segunda. Montes de enajenación dudosa. Tercera. Montes que se declaran desde luego en estado de venta." (R.D. 26 de octubre de 1855)

El segundo tipo establecido -no enajenables sin previo conocimiento científicosuscitó el recelo de la Administración que, por R.D. de 27 de Febrero de 1856, los incluyó también entre los vendibles. Finalmente, por R.O. de 6 de marzo de 1856, se promulgaron las Instrucciones que debían regular la ley desamortizadora. Se diferenciaron cuatro categorías de montes: los poblados con especies exceptuadas por el R.D. de 27 de febrero de 1856, los que se reservaban por razones graves de interés público, los de aprovechamiento común y, finalmente, los declarados en venta. E1 proceso concluyó -tras una serie de medidas matizadoras (R.O. de 11 de julio de 1856)con los R.D. de 2 de octubre de 1858 y 16 de febrero de 1859, que, asumiendo los criterios de clasificación del R.D. de octubre de 1855, sentaron las bases para la Clasificación General de los Montes Públicos de 1859 (MAPA-ICONA, 1990).

Los ayuntamientos del Pirineo occidental oscense -que venían reclamando el carácter comunal de sus montes- reaccionaron con rapidez y elevaron numerosas alegaciones. Por limitaciones de procedimiento, que pretendían favorecer -desde la Administración central- el individualismo municipalista (MANGAS, 1984), las Juntas y Comunidades no podían tramitarlas; cabría preguntarse hasta qué punto el ayuntamiento de un pueblo, aunque ostentara su capitalidad, era legítimo representante de los intereses del común de vecinos del Valle ${ }^{6}$.

Sirva como ejemplo el escrito tramitado por la corporación municipal de Ansó el 26 de febrero de $1859^{7}$. El documento insistía en la posesión y libre disfrute por los vecinos de unos montes propiedad del Valle y de los que disponían libremente salvo en lo relativo a los pastos en los tres meses de verano, durante los cuales se arrendaban los sobrantes a forasteros, garantizando la absoluta prioridad de los habitantes del Valle

\footnotetext{
5 "Art 2. Son de la primera clase los montes de abetos, pinabetes, pinsapos, pinos, enebros, sabinas, tejos, hayas, castaños, avellanos, abedules, alisos, acebos, robles, rebollos, quejigos y piornos, cualesquiera que sean sus especies, su método de beneficio y la localidad donde se hallaren. Art. $3^{\prime \prime}$ Corresponden a la segunda clase los alcornocales, encinares, mestizales y coscojales, en cualesquiera que sean sus variedades y sus métodos de beneficio (...) Art. $4^{\text {* }}$ Pertenecen a la tercera clase las fresnedas, olmedas, lentiscales, cornicabrales, taraales, alamedas, saucedas, retamares, acebuchales, almezales, bojedas, jarales, tomillares, brezales, palmitares y demás montes no comprendidos en los dos artículos anteriores."

${ }^{6}$ EI Valle como demarcación supramunicipal intrínseca al Pirineo estaba entonces más viva que en la actualidad. DE TORRES (1971) analiza este hecho en el noroeste de Navarra.

7 Este largo texto, que no traemos aquí, está reproducido en VALENZUELA (1969).
} 
mediante el pago de un canon simbólico. Se reconocía el derecho libre a leñar, así como la existencia de cultivos en el monte; finalmente se detallaban las partidas destinadas -en cuanto boalares- al ganado de labor y carnicería. Se perseguía así el reconocimiento del carácter comunal y el intento de acogerse a excepción en los dos supuestos de aprovechamiento común y boalar; se argumentaba, además, la necesidad del mantenimiento de estos aprovechamientos para la pervivencia del Valle.

La resolución a las anteriores alegaciones del Ayuntamiento de Ansó fue tramitada el 19 de mayo de 1859, declarando sus montes como terrenos de propios con servidumbre de pastos a favor de los ganados de los vecinos; ello suponía el reconocimiento del carácter vecinal, pero no el de aprovechamiento común. La simultaneidad de esta resolución con las disposiciones que confluyeron en la Clasificación de 1859, en la que estos montes -junto a una gran parte de los Altos Valles jacetanos- quedaron excluídos de venta por causas de utilidad pública, explica el hecho de que el escrito quedara sin contestación.

Los datos aportados por esta Clasificación General de los montes públicos de 1859 permiten conocer cuáles fueron las superficies declaradas desamortizables en la comarca. En el conjunto provincial oscense se registraron como enajenables 157 montes con una extensión de 18.798 has, ello suponía el 11\% del número y el $9 \%$ de la superficie total de los públicos. Son proporciones muy inferiores a las del conjunto nacional, que presentaba un 35\% de los montes públicos como enajenables ( $34 \%$ de la superficie). Menor aún es la relación para la Jacetania ${ }^{8}$ : tan sólo 435 has enajenables, el $019 \%$ en términos de superficie (de las 47.823 has de montes públicos) ${ }^{9}$. En definitiva, una exigua superficie que permitiría obviar la incidencia de esta primera desamortización -piénsese que se trata de montes enajenables, no enajenados- de no considerar el muy relevante proceso de cambio en la titularidad -de los vecinos al ayuntamiento- que se consolidó, en gran medida, de forma simultánea y que puede considerarse una usurpación quizá de mayor importancia que la propia venta.

Pero el proceso desamortizador no se detuvo en este momento: mediante R.D. de 22 de enero de 1862 se establecieron nuevas reglas para la excepción de venta de montes públicos, determinándose como condición mínima el que constaran al menos de 100 has (superficie calculada acumulando la de los motes que distaran menos de $1 \mathrm{~km}$ ) ${ }^{10}$. Los

8 La forma de presentación de los datos - por partidos judiciales y pueblos- y el gran número de anexiones y particiones municipales en estos 130 años ha obligado -del mismo modo que para los catálogos que se citan más adelante- a una labor de homogeneización compleja.

9 Ocho montes con una reducida superficie que tan sólo supone el $02 \%$ de la comarcal; únicamente son significativos los casos de Acumuer y Biescas (4'9\% y $16 \%$ de sus términos).

10 El texto de la R.O. de 22 de enero de 1862, que desarrolla este decreto, señala: "Art. 1 En virtud de dicho Real Decreto, solo quedan exceptuados de la venta, con arreglo al articulo $2^{\prime}$ de la ley de $1^{\circ}$ de mayo de 1855, los montes cuya especie arbórea dominante sea el pino, el roble o el haya, y que cubran una extensión lo menos de 100 has. $2^{\prime}$ Todos los terrenos que no contengan pino, roble ni haya quedan desde luego en estado de venta, sin necesidad de más trámites ni declaraciones por 
nuevos criterios suponían un incremento en la superficie desamortizable al contemplar la posibilidad de que fueran vendidos montes de reducido tamaño aunque las especies presentes fueran objeto de excepción. Se estableció, asimismo, la formación de un segundo Catálogo, en este caso sólo de montes exceptuados (CATÁLOGO..., 1864).

En los años siguientes se dictaron disposiciones tendentes al reconocimiento de los usos vecinales, aunque casi nunca, por supuesto, otorgándoles el carácter de comunales: por R.O. de 4 de junio de 1862 dictaminó, por ejemplo, que los usos vecinales debidamente acreditados debían respetarse ${ }^{11}$. En esta línea se inscribe también la contestación del Ministerio de Fomento al escrito que había elevado el ayuntamiento de Ansó: mediante R.O. de 29 de abril de 1864 se consolidaba el carácter vecinal de sus aprovechamientos en los términos tradicionales 12 , derecho que sería confirmado posteriormente (R.O. de 10 de diciembre de 1898 y R.O. 6 de marzo de 1920). Para las cortas de madera, en cambio, una R.O. de 21 de diciembre de 1883 estableció que no podían liberarse de la obligación de adjudicación por subasta en tanto no existiera una declaración administrativa que las considerara como de común aprovechamiento.

Durante los cuatro últimos decenios del pasado siglo, y hasta que el Decreto-Ley de 3 de marzo de 1917 suspendiera las leyes desamortizadoras en lo referente a pueblos y provincias, el proceso se intensificó por el aumento de la superficie enajenable que propició el R.D. de 1962. La valoración de la incidencia en la comarca puede abordarse a través de los datos de dos interesante fuentes: la Relación de montes públicos enajenables (MINISTERIO DE FOMENTO, 1893) y la Relación de los montes y demás terrenos forestales de dominio público que no revisten interés general ${ }^{13}$, realizada en cumplimiento del R.D. de 27 de febrero de 1897 (GACETA DE MADRID, 1897).

Aunque la superficie declarada enajenable en 1893 -943 has- fue más del doble de la incluída en 1859, la proporción del monte público afectado continuó siendo

parte del ministerio de fomento o sus dependencias. 3" Los terrenos que contengan alguna de las tres especies de arboles expresado podrán se vendidos, previo informe del ingeniero de montes que certifique que ninguna de las tres es dominante en el, o que la extensión de la finca no llega a 100 hectáreas."

11 A la vista de diversos expedientes, como el remitido por la Comunidad de Albarracín, esta R.O. dispuso que "deben respetarse en toda su integridad los usos legítimamente establecidos y plenamente acreditados en cada localidad para el aprovechamiento de los montes."

I 2 Este texto declara: "En vista de los documentos remitidos por V.S. en los que se justifica el derecho que tienen los ganaderos de Ansó a que disfruten sus ganados de las yerbas de verano de los montes comunes: S.M. Ia Reina (q.D.g.) se ha servido declarar subsistente el derecho mencionado, con cuyo motivo deberán los ganaderos satisfacer a razón de veinte marevedises por cada cabeza de las que utilicen los pastos que fueron autorizados por Real Orden de 26 de Mayo del año próximo pasado."

13 Incluye tanto montes de aprovechamiento común y dehesas boyales que por el carácter de su aprovechamiento se declaraban no enajenables como los demás montes vendibles. Sobre la utilidad y explotación de esta fuente a escala nacional, ver MANUEL Y OT. (1991). 
ínfima ${ }^{14}$. En la relación de 1897, en cambio, eran ya 2.038 has, lo que suponía el 4'3\% de la total pública según el catálogo de 1859; 61 montes que comprendían el 1\% de la superficie total (MAPAS 1 y 2). Las entidades afectadas se localizan en la mitad Sur de la comarca -especialmente una franja longitudinal a lo largo de la Depresión Media-con las excepciones de Acumuer y Aísa; aunque no disponemos de datos, parece probable que la desamortización tuviera cierto protagonismo en estas entidades, ello explicaría en parte la existencia de propiedades forestales privadas (colectivas y particulares). En la mayor parte de los casos las superficies enajenables de las tres relaciones correspondían a partidas diferentes, por lo que las superficies podrían -con ciertas reservas- sumarse. De esta manera se alcanzaría un total enajenable -no por ello enajenado- de 3.416 has, el 7'1\% del total de montes públicos en 1859 15; la toponimia nos remite a montes normalmente cubiertos por boj y quejigo.

Son pocas las noticias sobre ventas que hemos podido localizar. Según GARCÍA RUIZ (1974) estas propiedades de la desamortización civil salían a la venta en parcelas más pequeñas que las de la eclesiástica, lo que propició la participación de pequeños propietarios -vecinos de los pueblos- que accedían a la tierra de forma colectiva, mediante Sociedades de vecinos, o, individualmente, mediante distribución en lotes. Interesante a este respecto es el caso de Villanúa: 51 de sus 164 propietarios según el Catastro actual tienen idénticas superficies de monte bajo y maderable ${ }^{16}$. E1 Registro del estado legal de los montes (Archivo Histórico de Huesca) proporciona tan sólo información detallada sobre ventas efectuadas en el Monte de Utilidad Pública 218 (Berdún). Aun tratándose de un caso aislado, puede resultar ilustrativo: la partida denominada Transveral -151 has- fue vendida a un particular en 1898, sin que conste 1 a invalidación de la venta; la partida llamada Larota, antes del Comín de vecinos de Berdún y con derecho a pastos por el pueblo de Biniés (según alero foral fechado en 1685), fue igualmente vendida en 1876, operación declarada nula por R.O. de 9 de noviembre de 1877 de la Dirección General de Propiedades.

Con el Catálogo de Montes de Utilidad Pública de 1901 y el cierre definitivo del proceso desamortizador en 1917 se pueden dar por concluídas las transformaciones

\footnotetext{
14 Son 16 montes que incluyen el 0'3\% de la superficie comarcal; los términos más afectados son de la mitad Sur, si bien el caso más significativo es el de la Partida del Baño en Hecho (402 has).

15 LLOP Y MATA (1989) y MATA Y LLOP (1989) manifiestan la práctica imposibilidad de determinar la superficie vendida por mero saldo entre inventarios dada la modificación de criterios en su elaboración; aunque se refieren a los de 1859 y 1901, la observación es también válida en este caso. Los problemas relacionados con la segregación/agrupamiento de montes han sido resueltos con el riguroso análisis de su denominación. En definitiva hablaremos de superficie vendible o enajenable y no enajenada, siempre como mera aproximación.

16 Concretamente: 0'0420 ó 0'0240 has de monte bajo, 0'1020 de monte maderable de 1'a $0^{\prime 2} 2470$ de $2^{a}, 0^{\prime} 1190$ de $3^{\mathrm{a}}, 0^{\prime} 0930$ ó 0'1150 de $4^{\mathrm{a}}$; con frecuencia en las mismas partidas. Es significativa también la pertenencia de los montes de UP 319-320 a Villanúa y Señorío de Aruej, ello podría indicar la preexistencia de una propiedad que habría derivado en tal fragmentación por venta.
} 


\section{MAPA 1: División administrativa: entidades catastrales (Jacetania)}
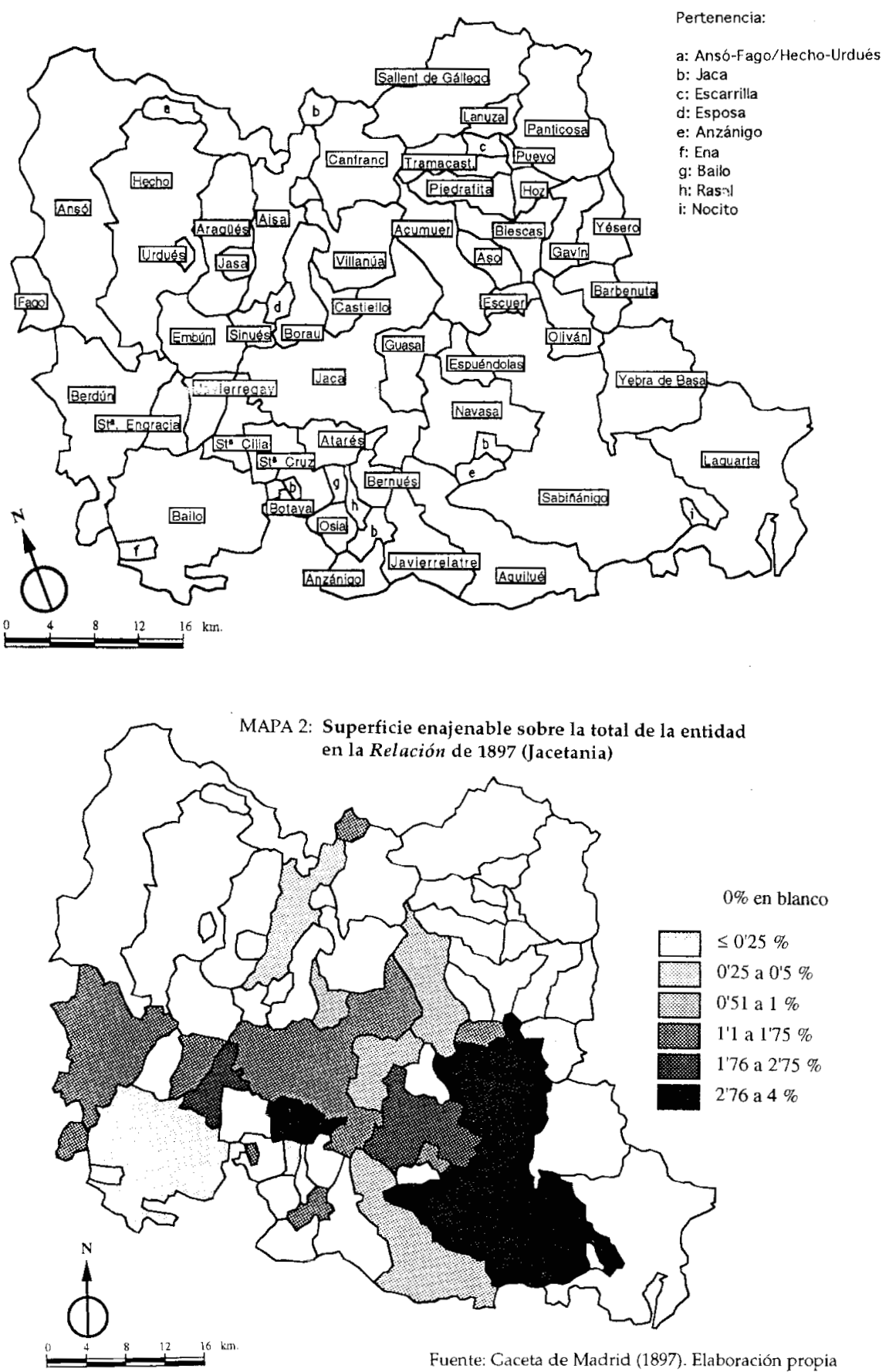
político-administrativas de los montes que se viene considerando en estas páginas. Existe un documento-R.O. de 6 de marzo de 1920- que refleja con claridad cuáles eran los posicionamientos de la Administración en este momento en el que, además, la política forestal del Estado estaba ya encauzada en el marco de la teoría selvícola alemana. La citada disposición contestaba al escrito de protesta que, por la subasta pública de la totalidad de los pastos en el plan de aprovechamientos de 1919-1920, habían remitido diversos municipios pirenaicos de la Jacetania (Ansó, Fago, Panticosa, El Pueyo y Hoz de Jaca) y del Sobrarbe.

El recurso interpuesto por los pueblos alegaba el carácter vecinal del aprovechamiento y solicitaba la suspensión de las subastas; la citada R.O. se manifestó conforme a la petición, haciéndolo extensivo a los demás pueblos que así hubieran realizado sus aprovechamientos en los veinte años anteriores ${ }^{17}$. Aunque se reconocía el carácter vecinal de los usos de los pastos, se señalaba la necesidad de que estuvieran avalados por títulos legítimos y no en malas prácticas a que se ha dado legalmente el nombre de costumbre. Al propio tiempo se estimaba que la explotación vecinal de pastos beneficiaba tan sólo a algunos ganaderos y que debía ser limitada a lo imprescindible; por otra parte, se afirmaba con rotundidad la incompatibilidad de los aprovechamientos vecinales de pastos con la conservación de los montes.

\section{LOS MONTES JACETANOS EN LOS CATÁLOGOS (1859， 1864， 1893, 1897/1901) 18}

Los Catálogos son registros administrativos que no prejuzgan la posesión, tan sólo la acreditan, para aquellos montes incluídos, en caso de no existir conflicto (R.D. de 1 de febrero de 1901). La información que presentan y su forma de presentación es variable. El de 1859 recoge los montes por ayuntamientos y pueblos, aportando su

17 Un extracto de esta R.O. de 6 de marzo de 1920: "Vista la instancia elevada por los alcaldes (...) en súplica de que los aprovechamientos de pastos de sus montes (...) les sean concedidos vecinalmente en el año actual y sucesivos, en atención a que vienen verificándose de esa manera desde tiempo inmemorial en virtud de antiguas concesiones reales (...) Resultando que según se informa (...) venían concediéndose aprovechamientos de pastos vecinales a los pueblos casi sir interrupción, durante más de veinte años, si bien consta que el Ayuntamiento de Hecho sin interrupción subastaba parte de ellos (...) Que los derechos de uso, aprovechamientos o servidumbres con que estuvieren gravados los montes, deben estar apoyados en títulos legítimos y no en malas prácticas a que se ha dado legalmente el nombre de costumbre (...) Que estando reconocida la incompatibilidad de los aprovechamientos vecinales de pastos con la conservación de los montes (...) deben limitarse aquellos a lo estrictamente necesario (...) Que en los aprovechamientos vecinales de pastos no disfrutan por igual todos los vecinos (...) S.M. el Rey (...) se ha servido disponer sean atendidas las reclamaciones (...) reconociéndoles el derecho al disfrute vecinal de pastos por adjudicación a los respectivos ayuntamientos de los puebios (...)."

18 Los catálogos han estado en el punto de mira de autores que han valorado su utilidad y los han analizado a diferentes escalas. Destacan los trabajos de LLOP Y MATA (1989), MATA Y LLOP (1989), MONTIEL (1990), MANUEL Y OT. (1991), IRIARTE (1992) Y MONTIEL (1992). 
nombre, cabida aforada y especies dominante y subordinadas. El de 1864, en cambio, reúne los montes por municipios, detallando el pueblo al que pertenecen junto a su nombre y límites; la especie subordinada ya no aparece y se introduce como novedad sustancial una numeración correlativa. El de 1901 mantiene esta estructura, aunque añade la información de la cabida forestal, casi siempre coincidente con la total.

Como ya se ha adelantado, los criterios para la inclusión de los montes variaron en el tiempo. El de 1859 contempló la totalidad de los montes públicos, diferenciando entre enajenables y exceptuados (de aprovechamiento común y dehesas boyales), detallando según la pertenencia fuera del Estado, de los pueblos o de las corporaciones civiles ${ }^{19}$. En cambio, el de 1864 tan sólo incluyó los exentos de desamortización ${ }^{20}$, del mismo modo que el de 1901. Este último se fundó en el criterio de utilidad pública y se apoyó en una singular diferenciación de la zona forestal (R.O. de 21 de noviembre de 1896); la novedad más interesante fue la inclusión de los yermos impropios para el cultivo agrario permanente situados en elevadas mesetas o paramos y en las fuertes pendientes, siempre que los tales montes yermos tengan por lo menos cabida de 100 hectáreas con objeto de repoblación (GÓMEZ-MENDOZA, 1992) 21.

El tratamiento de estos datos implica, como consecuencia de los cambios en su forma de presentación, un trabajo de homogeneización y homologación por montes y municipios; en la práctica obliga a un seguimiento por montes en los listados y, simultáneamente, en la cartografía topográfica. Sólo de este modo se pueden considerar correctamente las numerosas agregaciones habidas entre los diferentes listados, así como incluir en el análisis las relaciones de montes de 1893 y $1897^{22}$. En e 1 Catálogo de 1859 la totalidad de los montes jacetanos -tanto exceptuados como enajenables- se incluyen entre los pertenecientes a los pueblos; en cambio, el de San Juan de la Peña se registra como propiedad de la Diputación provincial oscense en 1864 y del Estado en 1901. En los dos registros de montes enajenables (1893 y 1897) los pueblos figuran, en todos los casos, como los propietarios.

\footnotetext{
19 Realizado según R.D. de 16 de febrero de 1859 y R.O. de 17 de Febrero de 1859, fue aprobado por R.O. de 30 de septiembre de 1859; siguió las directrices de las R.O. de 1 de mayo de 1855 y 11 de julio de 1856 con los criterios de clasificación del R.D. de 26 de octubre de 1855.

20 El R.D. 22 de enero de 1862 -y R.O. de la misma fecha- habían establecido nuevos criterios de excepción; tres meses más tarde se planteó ya -R.O. de 12 de abril- una rectificación; el catálogo se elaboraría, finalmente, según la Ley de 24 de mayo de 1863 , que introdujo -junto al criterio de especie- el de superficie superior a 100 has para posibilitar la excepción.

${ }^{21} \mathrm{La}$ R.O. de 24 de diciembre de 1896 matizaba: "4" La circunstancia de ser un monte de aprovechamiento común o dehesa boyal no se estimará suficiente para que el predio quede comprendido en el Catalogo de los exceptuados por Fomento, si no reúne a la vez el carácter de utilidad publica (...)". El Catálogo fue aprobado mediante el R.D. de 1 febrero de 1901.

22 El hecho de que los catálogos de 1864 y 1901 atiendan únicamente a los exceptuados ha hecho preciso, para conocer la totalidad del monte público, considerar conjuntamente el Catálogo de 1901 y el Registro de enajenables de 1897.
} 
La superficie del monte público en 1859 sería de 47.823 has, el 17\% de la comarca (únicamente 435 has enajenables). El porcentaje de superficie exceptuada según el Catálogo de 1864 -49.625 has- presenta tan sólo diferencias mínimas con respecto al de 1859 y, dada la exigua superficie enajenable en este último año, a la total pública; entre estos dos registros el número de montes implicados aumenta de 153 a 176 . El cotejo de la superficie real de los montes con la asignada en los catálogos evidencia una gran subestimación 23 ; además de cierta posible intencionalidad hay que considerar 1 a pobreza de medios planimétricos y el entonces deficiente conocimiento de estos montes.

Bien distinta es la situación que reflejan los datos de 1897/1901, advirtiéndose un considerable incremento del monte público (MAPA 3); significativo es el caso de Aragüés, que pasan de abarcar el $9 \%$ de su superficie total al $88 \%$, cifra más próxima a la realidad actual. Junto a la mejora en las condiciones técnicas de planimetría, y el mayor conocimiento del monte, es perceptible la ampliación del criterio de excepción

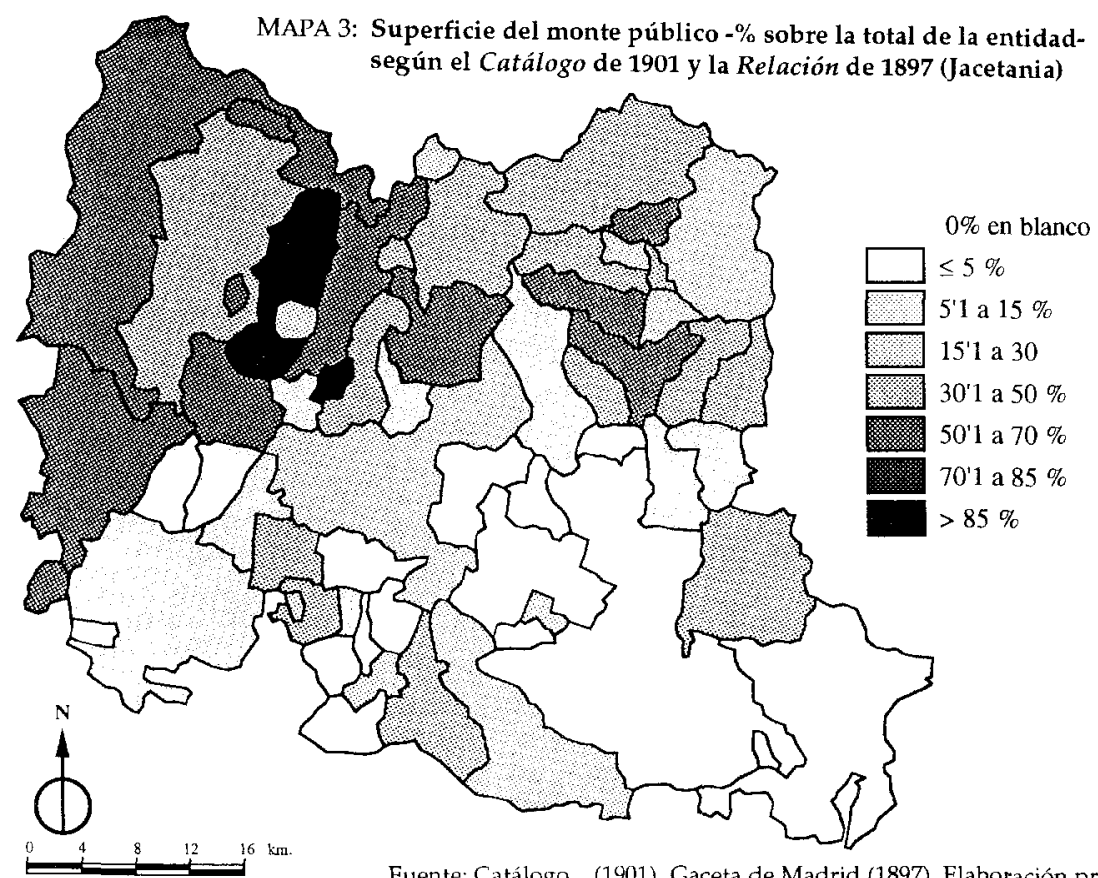

Fuente: Catálogo... (1901), Gaceta de Madrid (1897). Elaboración propia

\footnotetext{
23 La determinación de la superficie incluída en los montes de los distintos listados puede hacerse a partir de la denominación, la descripción de los límites y, en ocasiones, la cartografía forestal de la época. A este respecto es de gran interés el Croquis Especial de los montes del Valle de Ansó realizado en 1859 y que sirvió de apoyo al Catálogo de dicho año; aunque los datos de este Valle son medianamente válidos, los errores en la cartografía son muy evidentes.
} 
al amparo del concepto de utilidad pública. Según estos últimos datos, la superficie total del monte público -84.727 has- sería el 30\% de la total comarcal; el número de montes también aumenta considerablemente, pasando de 161 a 219 . El análisis por entidades catastrales, aunque con patente subestimación de los datos, permite diferenciar entre los Altos Valles -con porcentajes mayores de monte público- y 1 a mitad meridional -Depresión Media o al sur de ésta- con valores inferiores al 5\%.

Una forma de valorar en qué medida se subestimaron las superficies en estos catálogos es el cotejo con las cifras ahora oficiales; dado que determinados montes antes exceptuados -en especial en 1901- han sido más tarde objeto de consorcio o compra por la Administración para su repoblación, la superficie de referencia debe incluir tanto montes del Catálogo como del Elenco. Las superficies exceptuadas en 1859 se sitúan, mayoritariamente, entre el 5\% y el 30\% de las actuales de referencia; las mayores aproximaciones a la realidad (más del 50\%) se producen en Ansó-Fago, Esposa y Biescas (entre las entidades con mayor proporción de monte en Catálogo y Elenco, superior al 70\% del término); en Berdún, Gavín y Yebra de Basa (con proporción anterior entre el $30 \%$ y el $70 \%$ ), y en Botaya y Acumuer entre las que dicho porcentaje es inferior al 30\%. El mismo cálculo arroja valores casi idénticos para 1864. En 1901 la situación es mucho más próxima a la actual; el intervalo dominante es el de 50/75\%, existiendo un número de casos similar tanto por encima como por debajo de esta proporción. Donde los montes de utilidad pública son actualmente una parte muy significativa del término, la superficie exceptuada en 1901 supone entre el 30\% y el 75\% de aquélla; hay que tener en cuenta que el actual Catálogo de utilidad pública es prácticamente idéntico al de 1901 (con variaciones de superficie tras los deslindes).

Juntamente a las superficies de los montes, los catálogos aportan información relativa a la cubierta vegetal dominante, aunque este dato debe tomarse con reservas. En términos generales se observa en el año 1859 un predominio de los montes con pino, que constituyen más del $60 \%$ del total; distribuídos por toda la comarca, están especialmente presentes en los Altos Valles. Se exceptuaban también, conforme a 1 criterio de 1855, los montes dominados por abetos (Guarrinza) y abedules (Panticosa); los poblados por robles -algo más del 12\%- se sitúan en la mitad meridional, si bien se incluyen otros en el Valle de Tena (robledales de Escarrilla y de la solana de El Pueyo de J.). Los dominados por haya se localizan preferentemente en el sector noroccidental, así como en la umbría de Sallent (monte Pacino) y, más al sur, en Cillas y Cortillas.

El Catálogo de 1901 manifiesta un ligero incremento del número de montes dominados por pinos y un aumento mayor de los poblados por vegetación arbustiva o rasos. Son evidentes los nuevos criterios de excepción, que contemplaban la posibilidad de incluir espacios no arbolados bajo el concepto de utilidad pública. Así sucede con diversos montes de la cabecera de los ríos Gállego, Aragón y Osia, ocupados por pastos. La especie dominante en la mayor parte continúa siendo el pino, estando también 
presentes el abedul (Hoz de Jaca), el abeto (Selva de Castiello), el haya (cabecera del río Veral, Oza, Pacino, Panticosa y Cortillas) y el roble (en los mismos montes que en 1859, a los que se añade el Boalar de Urdués).

En definitiva, la información aportada por estos catálogos -tanto de superficies como de especies- debe ser utilizada con suma cautela; sólo la verificación a escala de monte permite un análisis correcto, especialmente en el caso de estudios comparativos.

\section{EL MONTE PÚBLICO: DEFINICIÓN DEL CONCEPTO DE UTILIDAD PÚBLICA}

El actual Reglamento de Montes -22 de febrero de 1962- establece la división, según la pertenencia, entre particulares y públicos; estos últimos son los pertenecientes al Estado, a las Entidades locales y a las demás Corporaciones o Entidades de Derecho Publico, además de aquellos cuyo dominio útil, o parte de él corresponda al Estado o a cualquiera de las Entidades referidas (...) aunque el dominio directo pertenezca a un particular. Se incluyen, de este modo, los de utilidad pública 24.

Tal y como hemos constatado, la desamortización trajo como efecto positivo la catalogación de los montes y el interés creciente por su conocimiento. De este modo, el concepto de utilidad pública aplicado al espacio forestal tuvo su origen en los listados de montes exceptuados 25 ; todo ello fraguaría en el R.D. de 20 septiembre de 1896:

"A los efectos del art. 8 de la ley 30 de agosto último sobre modificación de impuestos, se entenderá que son montes de utilidad pública las masas de arbolado y terrenos forestales que por sus condiciones de situación de suelo y de área sea necesario mantener poblados o repoblar de vegetación arbórea forestal para garantizar, por su influencia física en el país o en las comarcas naturales donde tenga su asiento, la salubridad pública, el mejor régimen de las agua, la seguridad de los terrenos o la fertilidad de las tierras destinadas a la agricultura, revisándose con sujeción a este criterio el actual catálogo de los montes exceptuados por su especie y cabida."

El camino recorrido hasta la precedente definición había sido largo: desde la consideración exclusiva de ciertas especies forestales como exceptuables, hasta la afección de utilidad pública para terrenos que -aunque desprovistos de vegetación arbórea- fuera preciso repoblar. Son jalones en un proceso de valoración constante de la

24 En una segunda categoría, dentro de los montes públicos, se incluyen aquellos sobre los que la Administración forestal posee el dominio directo, mayoritariamente adquiridos para repoblación; un último tipo son los consorciados, en condominio entre la Administración (propiedad del vutelo o una parte del mismo) y un particular o entidad pública (propiedad del suelo o dominio directo).

25 Los de propios incluídos en Catálogo tienen estatus diferente a los otros bienes municipales; se asimilan a ellos los mancomunados o comunales atípicos, actualmente gestionados como de propios. Los comunales tienen un régimen jurídico similar tanto si están catalogados como si no lo están. 
función y vocación sociales del monte 26 , que se ha materializado crecientemente en nuestro ordenamiento jurídico contemporáneo (HERNÁNDEZ-GIL, 1976) 27.

El actual Reglamento de 1962 los define a partir de una serie de supuestos que podrían resumirse en el último de ellos (Art. 25, párrafo F) ${ }^{28}$ :

"Y en general, cuando se trate de masas de arbolado o terrenos forestales que, dadas sus condiciones de situación o de área, sea preciso conservar o repoblar por su influencia económica o física en la nación o comarca, la salubridad pública, el mejor régimen de las aguas, la seguridad de los terrenos, la fertilidad de las tierras destinadas a la agricultura o por su utilidad para la defensa nacional, previo requerimiento de la Autoridad militar."

Los criterios para la afectación de utilidad pública se mantienen, por tanto, en términos muy semejantes a los formulados en 1896; la diferencia más significativa se relaciona con la posibilidad de declaración en función de la influencia económica del monte, mientras que en aquella primera formulación tan sólo se valoraba el supuesto de influencia física, que, por supuesto, ahora también se contempla. Más aún, la actual definición ya fue formulada en términos idénticos en la Ley de 24 de junio de 1908 y el posterior Reglamento sobre conservación y repoblación (R.D. de 8 octubre de 1909).

Más recientemente se está propugnando desde diversos foros -con vistas a una nueva ley básica de montes y aprovechamientos forestales- una redefinición del concepto de utilidad pública. En esta línea, ABREU Y PIDAL (1985) ${ }^{29}$ propone una intervención mayor de la Administración, que debería adquirir o establecer convenios en los montes que reunieran determinadas características; este autor plantea la

\footnotetext{
26 A este respecto, entre las referencias anteriores, es interesante el Preámbulo de la Real Orden de R.O. de 21 de febrero de 1841: "Un adelanto debemos, sin embargo, a la legislación moderna sobre montes, y es que ha señalado y distinguido con bastante claridad las tres clases en que deben dividirse y los principios generales de administración que a cada una conviene aplicar: $1^{1}$ Montes de dominio particular (...) $2^{n}$ Montes comunes propios de los pueblos y de establecimientos públicos (...) $3^{a}$ Montes baldios y realengos, propiedad del Estado, cuya administración exclusiva corresponde al Gobierno."

27 Sobre todo en la regulación de la propiedad forestal en el derecho administrativo. Tal y como señala HERNÁNDEZ-GIL (1976), todo ello se manifiesta en la preocupación por la conceptualización legal del término monte, la consideración de su carácter público y la adopción de un régimen de atribuciones diverso a la propiedad en general.

28 Los anteriores supuestos son: 1. Los existentes en las cabeceras de las cuencas hidrográficas. 2. Los que en su estado actual o repoblados regulen el régimen hidrológico. 3. Los que eviten desprendimientos, fijen el suelo, defiendan poblados, eviten la erosión... 4. Los que saneen parajes pantanosos. 5. Los que con su aprovechamiento regular sirvan para hacer permanentes las condiciones higiénicas, económicas y sociales de los pueblos...

29 ABREU Y PIDAL (1985) opina que montes de utilidad pública serían "aquellos que, por las características del territorio en que se ubican (situación geográfica, topografía, altitud, pendiente, suelo, hidrología), de los sistemas biológicos (vegetación y fauna espontâneas) que éste alberga y de los recursos naturales renovables que generan, proporcionan satisfacción a necesidades de interés general público (relacionados con la calidad y nivel de vida de los españoles, tanto de carácter medio-ambiental, como relacionadas con la riqueza nacional o de la defensa nacional).'
} 
conveniencia -entre otras cuestiones- de llevar a cabo la gestión del monte por una. Administración especializada, que aunará la función tutelar con la permanente gestión para garantizar tanto la singularidad de las cuestiones administrativas, el uso y la utilización ordenada y racional de los recursos, como la protección.

\section{EL RESULTADO DE UN LARGO PROCESO: SIGNIFICACIÓN ACTUAL DEL MONTE DE UTILIDAD PÚBLICA EN LA JACETANIA}

La distribución de los predios actualmente declarados de utilidad pública en 1 a comarca -cuya cartografía a escala de monte puede encontrarse en DE LA RIVA (1993)es, por tanto, consecuencia directa de las exceptuaciones de desamortización y la catalogación consiguiente. Las más altas proporciones de este tipo de superficies sobre la total geográfica de las entidades catastrales se sitúan en aquellas ubicadas al norte de la Depresión Media y, en menor medida, en el entorno a las sierras conglomeráticas de la mitad meridional (MAPA 4) ${ }^{30}$. En los Altos Valles llegan a conformar una gran

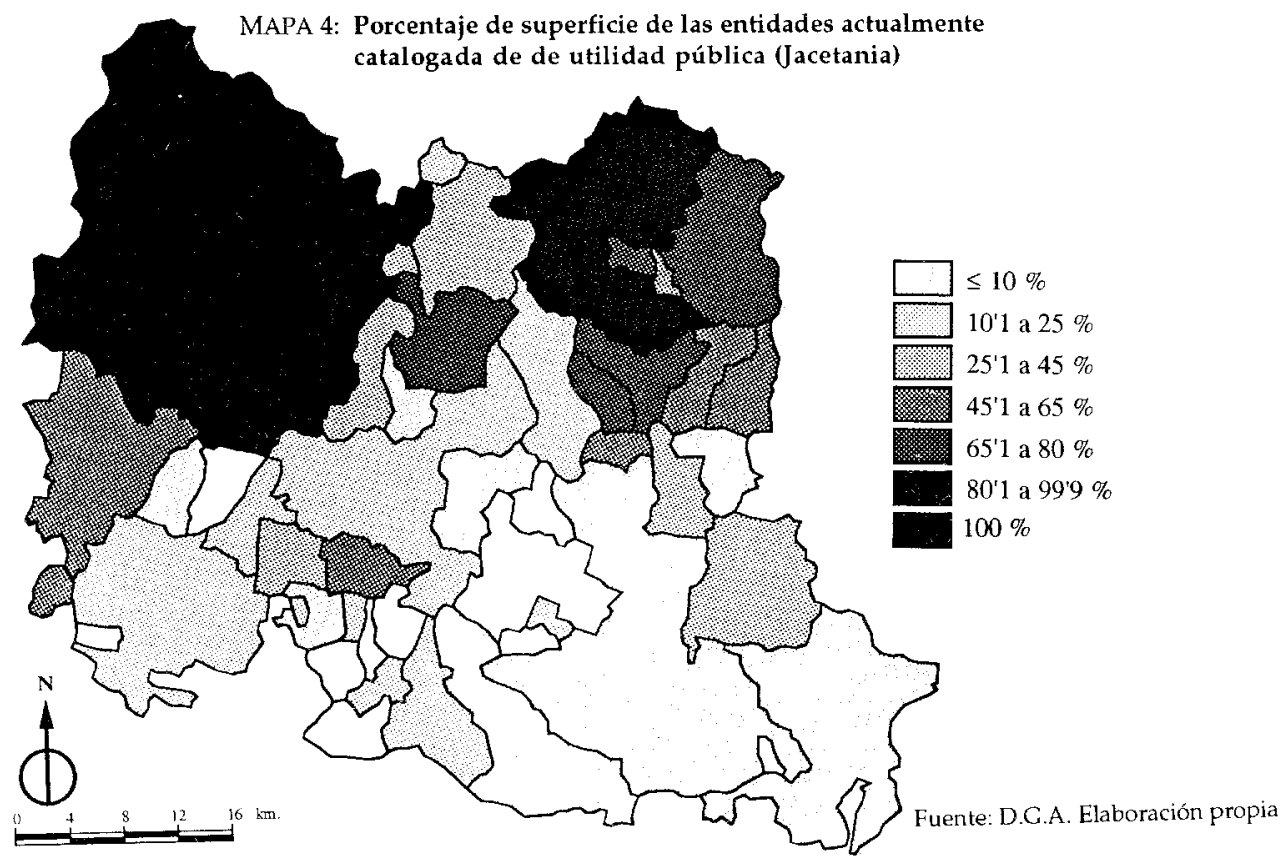

30 Ello no obsta para que, en régimen de enclavados, se incluyan dentro de casi todos estos montes de utilidad pública superficies particulares, normalmente reconocidas en el Catastro. 
mancha continua, sólo interrumpida por algunos sectores de propiedad privada colectiva o particular no incluídos en modalidad alguna de monte público (caso extremo de Acumuer) o por predios ahora del Elenco de los adquiridos por 1 a Administración para su repoblación (especialmente en el entorno de la Estación de Canfranc y en la Garcipollera, del término de Jaca) o consorciados con las entidades locales (de forma significativa en Borau y Panticosa).

La práctica totalidad de la superficie municipal está catalogada en Ansó-Fago, Hecho-Urdués y Aragüés-Jasa, Valles en los que son gestionados por mancomunidades forestales; algo menor, aunque superior al $80 \%$, es la relación en Embún y el Valle de Aísa. Proporciones máximas caracterizan también a diversas entidades del Valle de Tena (Sallent, Lanuza, Tramacastilla, Piedrafita y Hoz de Jaca); en tomo a este núcleo más oriental se encuentran las restantes entidades del Valle, así como las de la parte más septentrional del Serrablo (Aso de Sobremonte, Biescas, Gavín y Yésero), con una proporción de superficie declarada de utilidad pública entre el $45 \%$ y el $80 \%$. Se suma a ellos Villanúa, completando el conjunto de entidades que, al norte de 1 a Depresión Media, tienen una presencia significativa de este tipo de montes.

Canfranc, Borau, Castiello y Acumuer presentan porcentajes similares a los que aparecen en la mitad meridional de la comarca, en donde todas las entidades están por debajo del 25\% con excepción de Berdún, Atarés, Santa Cruz de la Serós, Yebra de Basa y Oliván (estas dos últimas parcialmente al norte de la Depresión Media). En seis entidades no existen superficies declaradas de utilidad pública, por ser zonas en las que el espacio cultivado o el monte bajo son dominantes (Javierregay, Espuéndolas, Bernués), o por tener sus montes destinados a repoblación (Anzánigo, Osia y Navasa).

Las consecuencias de la conformación del patrimonio forestal de utilidad pública no se agotan en su mera -aunque muy relevante- significación actual en el espacio comarcal. En cierto modo, las trasformaciones político-administrativas que afectaron a estos montes son una pieza clave en la explicación de su estado actual y de su dinámica más recientes. Los cambios en el sistema de gestión iniciados, en parte, de forma simultánea al proceso descrito y, en cualquier caso, favorecidos por él, supusieron una intensificación y regulación creciente de los aprovechamientos. Entre la segunda mitad del siglo pasado y los primeros decenios del actual, la Administración sentaría las bases legales de la explotación ordenada en el marco de la selvicultura alemana; se precisaba para ello un fuerte control sobre la propiedad forestal, que fue posible por la catalogación de amplios espacios. De este modo, algunos de estos montes contaron ya en fecha muy temprana -segunda y tercera décadas del siglo para los más noroccidentales- con Proyectos de Ordenación, en algún caso redactados por ilustres forestales como D. Octavio Elorrieta. Tan larga historia de aprovechamientos regulados por planteamientos con frecuencia productivistas ha tenido consecuencias paisajísticas, medioambientales, etc. muy importantes (DE LA RIVA, 1993 y 1996). 


\section{BIBLIOGRAFÍA}

ABREU Y PIDAL, J.M. (1985): "Reflexiones para la elaboración de la Ley básica de montes y aprovechamientos forestales", Montes (5), 21-25. Madrid.

ALCUBILLA, (1879. y 1923): Diccionario de la Legislación Española, Aranzadi Edit., Pamplona.

CALVO PALACIOS, J.L. (1970): Aísa un valle pirenaico, Memoria de Licenciatura. Fac. de Filosofía y Letras, Univ. de Zaragoza.

CATÁLOGO... (1864) de los montes públicos exceptuados de desamortización, hecho por el Cuerpo de Ingenieros de Montes en cumplimiento de lo dispuesto por Real decreto de 22 de Enero de 1862, y Real Órden de la misma fecha. Provincia de Huesca, Imprenta Nacional, Madrid.

CATÁLOGO... (1901) de los montes y demás terrenos forestales exceptuados de la Desamortización por razones de utilidad pública. Formado en cumplimiento de lo dispuesto por el artículo 4 del R.D. de 1 de febrero de 1901, Imprenta de la Sucesora de M. Minuesa de los Ríos, Madrid.

COSTA, J. (1983): Colectivismo agrario en España, Instituto de Estudios Agrarios, Pesqueros y Alimentarios, Guara editorial, Madrid.

DE LAA RIVA FERNÁNDEZ, J.R. (1989): "Aproximación al estudio de las explotaciones colectivas en el Pirineo aragonés", Actas del V Coloquio de Geografia Agraria, 157-166, Univ. Santiago de Compostela.

DE LA RIVA FERNÁNDEZ, J.R. (1993): "Consideraciones sobre la ordenación de montes en el Pirineo Occidental Aragonés y su incidencia en el medio natural: el caso del valle de Ansó", Geographicalia 30, 125-143. Depto. Geografía y O.T., Univ. de Zaragoza.

DE LA RIVA FERNÁNDEZ, J.R. (1994): Los montes de la Jacetania. Caracterización física y explotación, Tesis doctoral. Depto de Geografía y Ord. del Territorio. Univ. de Zaragoza.

DE LA RIVA FERNÁNDEZ, J.R. (1996): "La política forestal y sus consecuencias ambientales en los Altos Valles del Pirineo occidental oscense", comunicación presentada al congreso Landnutzungswandel und Umweltveränderungen in Spanien, Albert-Ludwigs-Universität Freiburg, Alemania, (en prensa).

DE TORRES LUNA, P. (1971): La Navarra húmeda del noroeste, Instituto de Geografía Aplicada del Patronato "Alonso de Herrera" (C.S.I.C.), Madrid.

GACETA DE MADRID (1897): Relaciones de los montes y demás terrenos forestales de dominio público que no revisten carácter de interés general, formadas en cumplimiento del artículo 40 del R.D. de 27 de febrero de 1897, por la Comisión clasificadora de los montes públicos, Dirección general de Propiedades y Derechos del Estado, 2 de septiembre de 1897, $\mathrm{M}^{\circ}$ ' de Hacienda.

GARCÍA DE ENTERRÍA, E. (1976): "Las formas comunitarias de propiedad forestal y su posible proyección futura", Conferencias sobre Derecho y Propiedad forestal, ETSIM Sección Publicaciones, Univ. Politécnica Madrid.

GARCÍA RUIZ, J.M. (1974): Modos de vida y niveles de renta en el Prepirineo del Alto Aragón Occidental, Tesis Doctoral, Depto. Geografía, Fac. de Filosofía y Letras, Univ. de Zaragoza. 
GÓMEZ MENDOZA, J. (1992): Ciencia y politica de los montes españoles (1948-1936), ICONA, Madrid.

HERNANDEZ GIL, A. (1976): "Función social de la propiedad forestal", Conferencias sobre Derecho y Propiedad Forestal, E.T.S.I.M., sec. publicaciones, Univ. Politécnica de Madrid.

IRIARTE GOÑI, I. (1992): "Una aproximación histórica a las formas de privatización de los montes públicos en Navarra", Agricultura y Sociedad, 65, 175-216.

LLOP, M. Y MATA, R. (1989): "Los montes de propiedad pública en España a través de la Clasificación y los catálogos del siglo XIX (1959-1991)", Actas del V Coloquio de Geografía Agraria., pp.7-24, Univ. Santiago de Compostela.

MANGAS NAVAS, J.M. (1984): La propiedad de la tierra en España: Los patrimonios públicos, Instituto de Estudios Agrarios, Pesqueros y Alimentarios, M.A.P.A. Serie: Estudios, Madrid.

MANUEL VALDÉS, C.; MATA OLMO, R.; SAEZ POMBO, E.; FERNÁNDEZ GONZÁLEZ, I. (1991): "La propiedad pública forestal en el cambio de siglo: la relación de montes no catalogados de 1897", Actas del VI Coloquio de Geografia Rural, Depto. de Geografía, Univ. Autónoma de Madrid.

MAPA-ICONA (1990): Clasificación general de los montes públicos, MAPA-ICONA (edición facsimil de 1859, Ministerio de Fomento), Madrid.

MARTÍN RETORTILLO, C. (1944): Cuestiones jurídico-fiscales sobre los montes de los pueblos, Bosch, Barcelona.

MATA OLMO, R.; LLOP POMARES (1989): "Clasificación y catálogos de montes públicos en el marco de la legislación desamortizadora y forestal del siglo XIX", Actas del V Coloquio de Geografia Agraria, 117-126, Univ. Santiago de Compostela.

MINISTERIO DE FOMENTO (1893): Relación de montes públicos enajenables, Dirección General de Agricultura, Industria y Comercio, M. Romero, Impresor, Madrid.

MONTIEL MOLINA, C. (1990): Los montes de utilidad pública en la provincia de Alicante, Univ. de Alicante y Caja de Ahorros de la provincia de Alicante.

MONTIEL MOLINA, C. (1992): "Titularidad y régimen de aprovechamiento de los montes catalogados en la Comunidad de Valencia", Agricultura y Sociedad, 65, 389-414..

VALENZUELA FUERTES, M.C. (1969): "La explotación del territorio ansotano en el pasado", Libro Homenaje a A. Canellas, Fac. de Filosofía y Letras, 979-995, Univ. de Zaragoza.

\section{FUENTES DOCUMENTALES INÉDITAS:}

Catálogo de Montes de Utilidad Pública, Elenco de montes de propiedad del Estado y montes Consorciados con particulares y entidades locales y Proyectos de Ordenación de los montes de la comarca. Departamento de Agricultura, Ganadería y Montes (D.G.A.).

Libro de Cédulas de la Propiedad. Catastro de Rústica. Centro de Gestión Catastral y Cooperación Tributaria. Gerencia territorial de Huesca ( $\mathrm{M}^{\circ}$ de Economía y Hacienda).

Registro del estado legal de los montes. Archivo Histórico de Huesca, (Ref. A-375). 